\title{
Universal screening for hypothyroidism in pregnancy: is it necessary?
}

\author{
Meena Priyadharshini V.*, Seetha Panicker
}

Department of Obstetrics and Gynecology, PSG Institute of Medical Sciences and Research, Coimbatore, Tamil Nadu, India

Received: 14 June 2019

Accepted: 19 June 2019

\section{*Correspondence:}

Dr. Meena Priyadharshini V.,

E-mail: drmeenushiv@gmail.com

Copyright: () the author(s), publisher and licensee Medip Academy. This is an open-access article distributed under the terms of the Creative Commons Attribution Non-Commercial License, which permits unrestricted non-commercial use, distribution, and reproduction in any medium, provided the original work is properly cited.

\section{ABSTRACT}

Background: Thyroid diseases are one of the commonest endocrine disorders affecting women of reproductive age group, and hence constitute one important disorders complicating pregnancy. The objective of this study was to determine the importance of universal screening for hypothyroidism in pregnancy at the first antenatal visit and to formulate whether this routine screening is mandatory in our country.

Methods: This retrospective study was conducted in the year 2018 at PSG IMSR Hospital for all pregnant women who attended the first antenatal visit between Jan 2012 to Dec 2012 after obtaining ethical clearance. Pregnant women who were already taking treatment for hypothyroidism, diabetes mellitus, hypertension and those pregnant women who lost their follow up were excluded from the study.

Results: The incidence of subclinical hypothyroidism among antenatal women were $7.06 \%$. In our study the maternal complications like anemia $12(8 \%)$, preeclampsia $26(17.3 \%)$, gestational diabetes $25(16.7 \%)$, fetal growth restriction $8(5.3 \%)$, Oligohydramnios $13(8.7 \%)$, pre mature rupture of membranes $25(16.7 \%)$, placental abruption in 2 $(1.33 \%)$, APLA syndrome $2(1.33 \%)$, low birth weight $26(17.3 \%)$ were observed.

Conclusions: Universal screening for hypothyroidism is recommended for all antenatal women especially in iodine depleted country like India.

Keywords: Anemia, Gestational diabetes, Pre-eclampsia, Subclinical hypothyroidism, Thyroxine, Thyroid stimulating hormone

\section{INTRODUCTION}

Thyroid diseases are among the commonest endocrine disorders affecting women of reproductive age group, and hence constitutes one of the important medical disorders complicating pregnancy. ${ }^{1}$ About $2-5 \%$ of all pregnant women are reported to have some degree of hypothyroidism. $^{2}$ Subclinical hypothyroidism is a prevalent condition which may go unrecognised and has the potential to cause adverse maternal and fetal outcome. ${ }^{3}$ Sub clinical hypothyroidism defined as elevated serum thyrotropin level accompanied by normal serum thyroxin concentration. TSH plays a central role in screening and diagnosis of hypothyroidism.
Pregnancy complications with hypothyroidism include increased incidence of preeclampsia, abruptio placentae, anemia, and preterm labour. Unexplained still birth, fetal distress, low birth weight and neonatal hypothyroidism are perinatal complications. ${ }^{4}$

There has been a wide geographic variation in prevalence of hypothyroidism during pregnancy. Reports indicate it varies from $2.5 \%$ from the West to $11 \%$ from India also it is more in Asian countries compared to the West. ${ }^{5,6}$ In a recent study by Dhanwal et al, a high prevalence of hypothyroidism $(14.3 \%)$ was noted. ${ }^{7}$ Looking at these data the purpose of the study was to determine whether 
universal screening for hypothyroidism in pregnancy would prove to be beneficial in our country.

The objective of this study was to determine the incidence of hypothyroidism in pregnancy at the first antenatal visit and complications associated to formulate whether routine screening can be recommended in our country.

\section{METHODS}

This retrospective study was conducted in the year 2018 at PSG IMSR Hospital for all pregnant women attending the first antenatal visit between January 2012 to December 2012 after obtaining ethical clearance.

\section{Inclusion criteria}

- All pregnant women attending the antenatal OPD at the first antenatal visit and who delivered in our hospital.

\section{Exclusion criteria}

- Pregnant women who were already taking treatment for hypothyroidism, diabetes mellitus, hypertension and those who lost their follow up in our hospital.

The Sr.TSH is done as a screening tool for hypothyroidism for all antenatal women. The Sr.TSH reference range as per Indian thyroid society guideline 2015 was applied to diagnose hypothyroidism in pregnancy. Sr.TSH upper limit value is in the following range in each of the trimesters:

- $\quad$ First trimester $<2.5 \mathrm{mIU} / \mathrm{L}$

- Second trimester $<3.0 \mathrm{mIU} / \mathrm{L}$

- Third trimester $<3.5 \mathrm{mIU} / \mathrm{L}$

Sr.TSH $>2.5 \mathrm{mIU} / \mathrm{L}$ in the first trimester were treated with thyroxine supplementation after checking FT3 and FT4.

These patients were subjected to repeat Sr.TSH in second and third trimester and analysed whether they are treated adequately or inadequately based upon the trimester specific upper reference limit. The dose of drug was adjusted if required. More over all the subclinical hypothyroid and low risk (euthyroid) study participants were followed up till delivery and analysed for any maternal complications like preeclampsia, anemia, preterm labour, gestational diabetes, fetal growth restrictions, low birth weight in both the groups.

\section{Statistical analysis}

The data was entered in Microsoft excel spread sheet and analysed by Statistical Package for Social science (SPSS version 21) and chi square test.

\section{RESULTS}

In the present study total number of antenatal women who booked and delivered at PSG Hospital was 2124 of which the total number women with subclinical hypothyroidism were $150(7.06 \%)$. The total number of low risk deliveries (euthyroid) excluding chronic hypertension (10), overt diabetes (19) and overt hypothyroidism (25) were 1920 and these patients were also analysed for maternal complications.

Table 1: Demographic distribution of age, parity, gestational age at diagnosis.

\begin{tabular}{|llll|}
\hline \multirow{2}{*}{ Variables } & & \multicolumn{1}{c|}{$\begin{array}{l}\text { Number of } \\
\text { women }(\mathbf{n}=\mathbf{1 5 0})\end{array}$} & $\%$ \\
\hline \multirow{3}{*}{ Age } & $<20$ & 3 & $2 \%$ \\
\cline { 2 - 4 } & $20-24$ & 49 & $33 \%$ \\
\cline { 2 - 4 } & $25-29$ & 57 & $38 \%$ \\
\cline { 2 - 4 } & $30-34$ & 32 & $21 \%$ \\
\cline { 2 - 4 } & $>35$ & 9 & $6 \%$ \\
\hline \multirow{2}{*}{ Parity } & Primi & 85 & $57 \%$ \\
\hline \multirow{2}{*}{$\begin{array}{l}\text { Gestational } \\
\text { age at } \\
\text { diagnosis }\end{array}$} & Multi & 65 & $43 \%$ \\
\cline { 2 - 4 } & $<14$ weeks & 38 & $25 \%$ \\
\cline { 2 - 4 } & $15-28$ & 87 & $58 \%$ \\
\hline
\end{tabular}

The above table shows distribution of subclinical hypothyroidism among different age groups. The gestational age at which the hypothyroidism was diagnosed were more between 15 to 28 weeks $(58 \%)$. The total number of subclinical hypothyroidism diagnosed in the $>15$ weeks of gestational age was $75 \%$.

Table 2: Maternal complications in antenatal subclinical hypothyroidism.

\begin{tabular}{|ll|}
\hline Maternal complications & $\begin{array}{l}\text { Number of } \\
\text { cases } n=150\end{array}$ \\
\hline Anemia & $12(8.0 \%)$ \\
\hline Pregnancy induced hypertension & $26(17.3 \%)$ \\
\hline Gestational diabetes & $25(16.7 \%)$ \\
\hline Fetal growth restriction & $8(5.3 \%)$ \\
\hline Oligohydramnios & $13(8.7 \%)$ \\
\hline Previous caesarean section & $20(13.3 \%)$ \\
\hline Rh negative & $15(10 \%)$ \\
\hline Pre mature rupture of membranes & $25(16.7 \%)$ \\
\hline Low birth weight & $26(17.3 \%)$ \\
\hline
\end{tabular}

Table 2 shows the most common maternal complications among the subclinical hypothyroidism were PIH $17.3 \%$, low birth weight $17.3 \%$, PROM $16.7 \%$ and GDM $16.7 \%$.

\section{DISCUSSION}

The thyroid gland size increases by $10 \%$ in size during pregnancy in iodine-deplete countries and to greater 
extent by $10-20 \%$ in areas of iodine deficiency. Hence the thyroid hormone production, thyroxin (T4) and triiodothyronine (T3) increases by $50 \%$, along with a $50 \%$ increase in daily iodine requirement during pregnancy.
These physiological changes may result in hypothyroidism during pregnancy in iodine-deficient women.

Table 3: Comparison of complications between subclinical hypothyroidism and euthyroid in pregnancy.

\begin{tabular}{|c|c|c|c|c|}
\hline Complications & & Subclinical hypothyroidism & Low risk pregnancy (Euthyroid) & P value \\
\hline \multirow{2}{*}{ Anemia } & Yes & 12 & 48 & \multirow{2}{*}{$.000 *$} \\
\hline & No & 138 & 1872 & \\
\hline \multirow{2}{*}{$\begin{array}{l}\text { Pregnancy Induced } \\
\text { Hypertension }\end{array}$} & Yes & 26 & 70 & \multirow{2}{*}{$.000 *$} \\
\hline & No & 124 & 1850 & \\
\hline \multirow{2}{*}{ Gestational diabetes } & Yes & 25 & 84 & \multirow{2}{*}{$.000 *$} \\
\hline & No & 125 & 1836 & \\
\hline \multirow{2}{*}{ Fetal growth restriction } & Yes & 8 & 50 & \multirow{2}{*}{.561} \\
\hline & No & 142 & 1870 & \\
\hline \multirow{2}{*}{ Oligohydramnios } & Yes & 13 & 85 & \multirow{2}{*}{$.000 *$} \\
\hline & No & 137 & 1835 & \\
\hline \multirow{2}{*}{$\begin{array}{l}\text { Pre mature rupture of } \\
\text { membranes }\end{array}$} & Yes & 25 & 110 & \multirow{2}{*}{.210} \\
\hline & No & 125 & 1810 & \\
\hline \multirow{2}{*}{ Low birth weight } & Yes & 26 & 36 & \multirow{2}{*}{$.000 *$} \\
\hline & No & 124 & 1884 & \\
\hline
\end{tabular}

The prevalence of subclinical hypothyroidism in our study group was $7.06 \%$. A study conducted by Sapna C. Shah et al, in Karnataka shows a prevalence of sub clinical hypothyroidism of $9 \% .{ }^{8}$ Nambiar et al, conducted a study in Europe among Asian Indian pregnant women and said that the prevalence of hypothyroidism is about $7.2 \% . .^{9}$ In contrast to our study Rajput et al, conducted a study and said that the prevalence of hypothyroidism in pregnancy in northern India is $14.3 \% .^{10}$

Table 1 shows the demographic distribution of age, parity and gestational age at the diagnosis of subclinical hypothyroidism. Among the age distribution most of the women were below 30 years of age 109 patients $(73 \%)$. Among 150 subclinical hypothyroidism pregnant women 85 of them were primi gravid and 65 of them were multigravida. The gestational age at which subclinical thyroidism was diagnosed based upon the TSH value were more in the second and third trimester.

In our study Table 2 shows the maternal complications like anemia 12 (8\%), preeclampsia 26 (17.3\%), gestational diabetes 25 (16.7\%), fetal growth restriction 8 (5.3\%), Oligohydramnios $13(8.7 \%)$, pre mature rupture of membranes $25(16.7 \%)$, placental abruption in 2 $(1.33 \%)$, APLA syndrome $2(1.33 \%)$, low birth weight 26 $(17.3 \%)$, papillary carcinoma thyroid $1(0.66 \%)$ treated with neck radiation were observed. In our study there were $20(13.3 \%)$ patients who underwent caesarean section. Radha et al, in her study observed the maternal complications in subclinical hypothyroidism like anemia in $18(36 \%)$, preeclampsia in $13(26 \%)$, placental abruption in $2(4 \%)$, caesarean section in 20 (44\%), low birth weight baby $28 \% .^{11}$ Anupama et al, in her study observed that $0.65 \%$ women had APLA syndrome, $0.3 \%$ had history of neck irradiation. ${ }^{12}$

Table 3 shows the maternal complications correlation between subclinical hypothyroidism and low risk (euthyroid) antenatal women.

In the present study among 150 subclinical hypothyroidism patients who were treated with thyroxine supplementation, 60 patients were adequately treated and 90 were inadequately treated. The adequately treated patients were diagnosed in the first trimester and the inadequately treated patients were in the late second and third trimester. Maternal complications like anemia, pregnancy induced hypertension, gestational diabetes, oligohydramnios, low birth weight were statistically significant $(\mathrm{P}$ value $<0.05$ ) in subclinical hypothyroidism group comparing to euthyroid. Leung et al, in his study found that there was a significant increased incidence of pre-eclampsia (15\%) among inadequately treated subclinical hypothyroidism. ${ }^{13}$ Ajmani et al, also observed $22.3 \%$ of pre-eclampsia and $12.11 \%$ of low birth weight in his study. ${ }^{14}$ Fetal growth restriction and premarture rupture of membrane were not statistically significant $(\mathrm{P}$ value $>0.05$ ) in the subclinical hypothyroidism group compared to the euthyroid group.

\section{CONCLUSION}

The prevalence of subclinical hypothyroidism among the pregnant women in the present study is $7.06 \%$, most of the adverse maternal and fetal complications are observed 
in subclinical hypothyroidism. Since hypothyroid is easily treated, hence universal screening for hypothyroidism is recommended for all antenatal women especially in the first trimester to reduce the burden of adverse maternal and fetal outcome.

\section{ACKNOWLEDGMENTS}

Authors would like to thank Dr. Seetha Panicker, Emeritus Professor and HOD, Department of Obstetrics and Gynaecology, PSGIMSR, Coimbatore, Tamil Nadu, India.

Funding: No funding sources

Conflict of interest: None declared

Ethical approval: The study was approved by the Institutional Ethics Committee

\section{REFERENCES}

1. Studd J. Progress in Obstetrics and Gynecology, Volume 15. London. Churchill Livingstone: 2003:75-101.

2. Casey BM, Dashe JS, Wells CE, McIntire DD, Byrd W, Leveno KJ, et al. Subclinical hypothyroidism and pregnancy outcomes. Obst Gynec. 2005;105(2):23945.

3. Dhanwal DK, Prasad S, Agarwal AK, Dixit V, Banerjee AK. High prevalence of subclinical hypothyroidism during first trimester of pregnancy in North India. Indian $\mathrm{J}$ Endocrinol Metabol. 2013;17(2):281.

4. Sahu MT, Das V, Mittal S, Agarwal A, Sahu M. Overt and subclinical thyroid dysfunction among Indian pregnant women and its effect on maternal and fetal outcome. Archives Gynec Obst. 2010;281(2):215-20.

5. Männistö T, Vääräsmäki M, Pouta A. Perinatal outcome of children born to mothers with thyroid dysfunction or antibodies: A prospective population-based cohort study. J Clin Endocrinol Metab. 2009;94:772-9.

6. Wang W, Teng W, Shan Z, Wang S, Li J, Zhu L, et al. The prevalence of thyroid disorders during early pregnancy in China: The benefits of universal screening in the first trimester of pregnancy. Eur $\mathbf{J}$ Endocrinol. 2011;164:263-8.

7. Dhanwal DK, Prasad S, Agarwal AK, Dixit V, Banerjee AK. High prevalence of subclinical hypothyroidism during first trimester of pregnancy in North India. Indian $\mathbf{J}$ Endocrinol Metab. 2013;17:281-4.

8. Sapna IS. Prevalence and outcome of hypothyroidism in women attending antenatal clinic at J. J. M Medical College. Int J Reprod Contracept Obstet Gynecol. 2017;6(8):3537-9.

9. Nambiar V Jagtap VS, Sarathi V, Lila AR, Kamalanath S, Bandgar TR, et al. Prevalence and impact of thyroid disorders on maternal outcome in Asian-Indian pregnant women. J Thyroid Res. 2011;2011:429097.

10. Rajput R, Goel V, Nanda S, Rajput M, Seth S. Original article prevalence of thyroid dysfunction among women during the first trimester of pregnancy at a tertiary care hospital in Haryana. 2015;19:5-8.

11. Radha KR, Sugunan N, Resmy CR. Do we need to screen and treat pregnant women for subclinical hypothyroidism? A cross sectional study in a rural tertiary centre in Kerala, India. Int J Reprod Contracept Obstet Gynecol. 2017;6(3):781-6.

12. Dave A, Maru L, Tripathi M. Importance of Universal screening for thyroid disorders in first trimester of pregnancy. Indian J Endocrinol Metabol. 2014;18(5):735-8.

13. Leung AS, Millar LK, Kooning PP, Montorom, Mestman J. Perinatal outcome in hypothyroid pregnancies. Obstetric Gynaecol. 1993;81(3):349-53.

14. Nangia AS. Prevalence of overt and subclinical thyroid dysfunction among pregnant women and its effect on maternal and fetal outcome. J Obstet Gynaecol India. 2014;64(2):105-10.

Cite this article as: Priyadharshini VM, Panicker S. Universal screening for hypothyroidism in pregnancy: is it necessary?. Int J Reprod Contracept Obstet Gynecol 2019;8:2683-6. 